\title{
PREVALENCE OF NEUROSIS IN WOMEN
}

\author{
BY \\ W. LAWTON TONGE, \\ D. W. CAMMOCK, \\ JOHN S. WINCHESTER*, AND ELIZABETH N. M. WINCHESTER* \\ University Department of Psychiatry. Whiteley Wood Clinic, Sheffield
}

Every survey of the prevalence of neurosis in general practice records a rate in women almost double that in men. This investigation is an attempt to examine a possible cause for this disparity.

The patients studied in this survey constituted a rural general practice of 3,000. Data were collected from the general practitioner's disease index, the patient's record card, and the personal knowledge of the general practitioner, who had made the psychiatric diagnosis. Children under 15, schizophrenics, subnormals, and patients with organic psychoses were excluded. Temporary emotional upsets which subsided rapidly after a single consultation were noted but are not considered in this paper as contributing significantly to psychiatric morbidity and

"This investigation was carried out during the "elective period", in which students at the Sheffield Medical School can carry out studies of their own choice. sickness absence. The diagnoses remaining comprised mainly neurotic and depressive reactions, and from these an attempt was made to assess the effects of gainful employment on the prevalence of neurosis in women.

\section{RESULTS}

Temporary Emotional UpSets (Table I).-Although there is no material difference in the prevalence of temporary emotional upsets between employed and not employed women, there is a marked decrease in their prevalence in men.

ANXIETY AND Depressive Reactions.-Table I, showing the effect of employment, seems to indicate that to some extent employment is associated with a lower prevalence of neurosis in women.

TABLE I

PSYCHIATRIC ILLNESS AND EMPLOYMENT

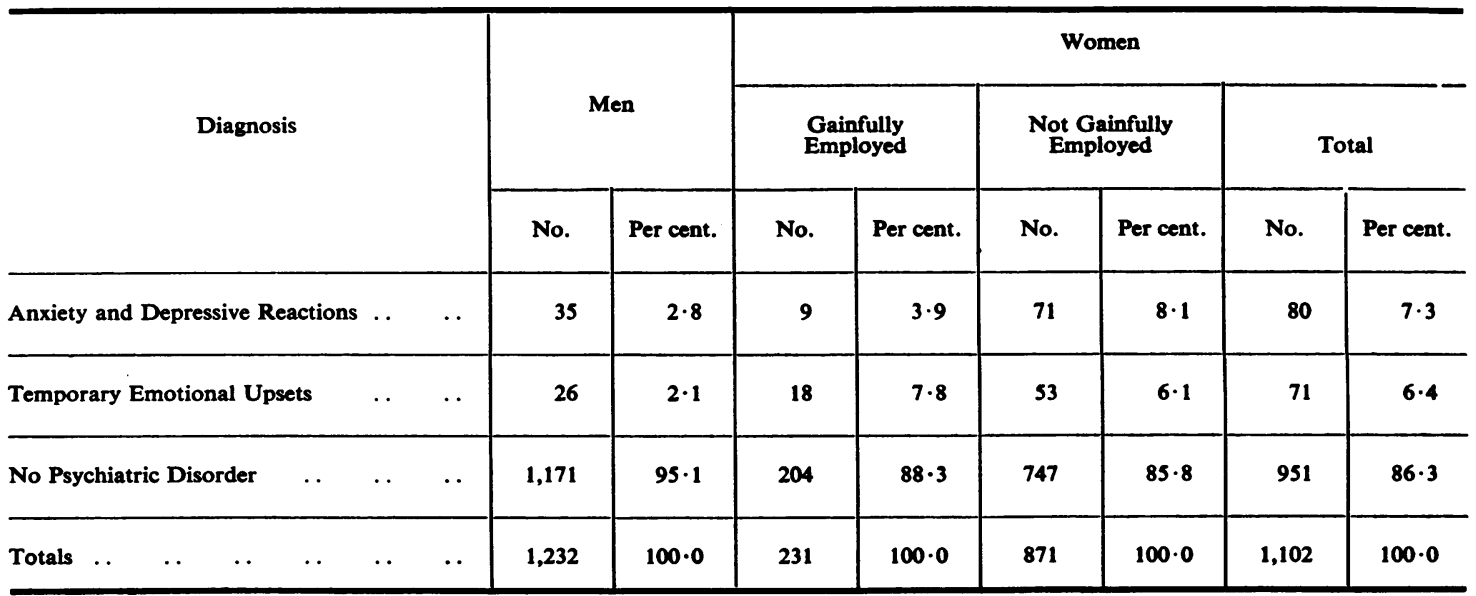


At this point, however, it is necessary to take into account the effects of age and civil status. Women over 60 are very rarely employed, yet contribute greatly to psychiatric morbidity rates. As only married women are likely to be able to choose whether to take up employment or not, single women were excluded.

Table II shows that the association between increased rate of psychiatric illness and lack of outside employment shown in Table $I$ is not confirmed when older age groups are excluded. A more detailed breakdown into age groups did not disturb this pattern. As recorded by other workers, the preponderance of women occurs in all age groups.

TABLE II

PSYCHIATRIC ILLNESS IN MEN AND WOMEN UNDER 60 YEARS

\begin{tabular}{|c|c|c|c|c|c|c|}
\hline \multirow{3}{*}{ Diagnosis } & \multicolumn{4}{|c|}{ Married Women } & \multirow{2}{*}{\multicolumn{2}{|c|}{$\frac{\text { Men }}{\text { Employed }}$}} \\
\hline & \multicolumn{2}{|c|}{ Employed } & \multicolumn{2}{|c|}{$\begin{array}{c}\text { Not } \\
\text { Employed }\end{array}$} & & \\
\hline & No. & $\begin{array}{l}\text { Per } \\
\text { cent. }\end{array}$ & No. & $\begin{array}{l}\text { Per } \\
\text { cent. }\end{array}$ & No. & $\begin{array}{c}\text { Per } \\
\text { cent. }\end{array}$ \\
\hline $\begin{array}{l}\text { Anxiety and Depres- } \\
\text { sive Reactions }\end{array}$ & 8 & $9 \cdot 4$ & 40 & $6 \cdot 9$ & 25 & $2 \cdot 6$ \\
\hline $\begin{array}{ccc}\text { No Psychiatric } & \text { Dis- } \\
\text { order } & . . & . \\
\end{array}$ & 58 & $90 \cdot 6$ & 537 & $93 \cdot 1$ & 936 & $97 \cdot 4$ \\
\hline Totals & 66 & $100 \cdot 0$ & 577 & $100 \cdot 0$ & 961 & $100 \cdot 0$ \\
\hline
\end{tabular}

Table III shows an association between widowed and married women and a higher rate of psychiatric disorder. Unfortunately the data did not provide an age breakdown of patients without psychiatric disorder in these different civil status groups, so that the probability of the effect on age still has to be borne in mind, in that the majority of single women belong to younger age groups with a low incidence of psychiatric disorder.

\section{Discussion}

Although a high female/male ratio is noted in all prevalence studies of psychiatric disorder, as far as the writers are aware there have been no published attempts to isolate possible factors relevant to this finding. Logan and Cushion (1958) showed that this ratio did not hold for all disease groups and Stein (1960) was able to show that the number of consultations in women was unrelated to marital state, number of children, or employment, which suggests that the housewife does not visit the doctor more frequently merely because she has more opportunity.

A period prevalence study such as this is not the most refined tool in epidemiological investigations, and it is felt that an inception study of psychiatric disorder amongst women both employed and not employed is necessary before the effect of occupation can be ruled out. Brown, Carstairs, and Topping (1958) have already shown the beneficial effect of occupation in chronic schizophrenia, so it is not unreasonable to suppose that it would have a similar stabilizing effect in women. It has also been shown that prolonged unemployment in men can lead to psychological disturbance (Morton, 1935; Eisenberg

TABLE III

PSYCHIATRIC ILLNESS AND CIVIL STATUS OF WOMEN

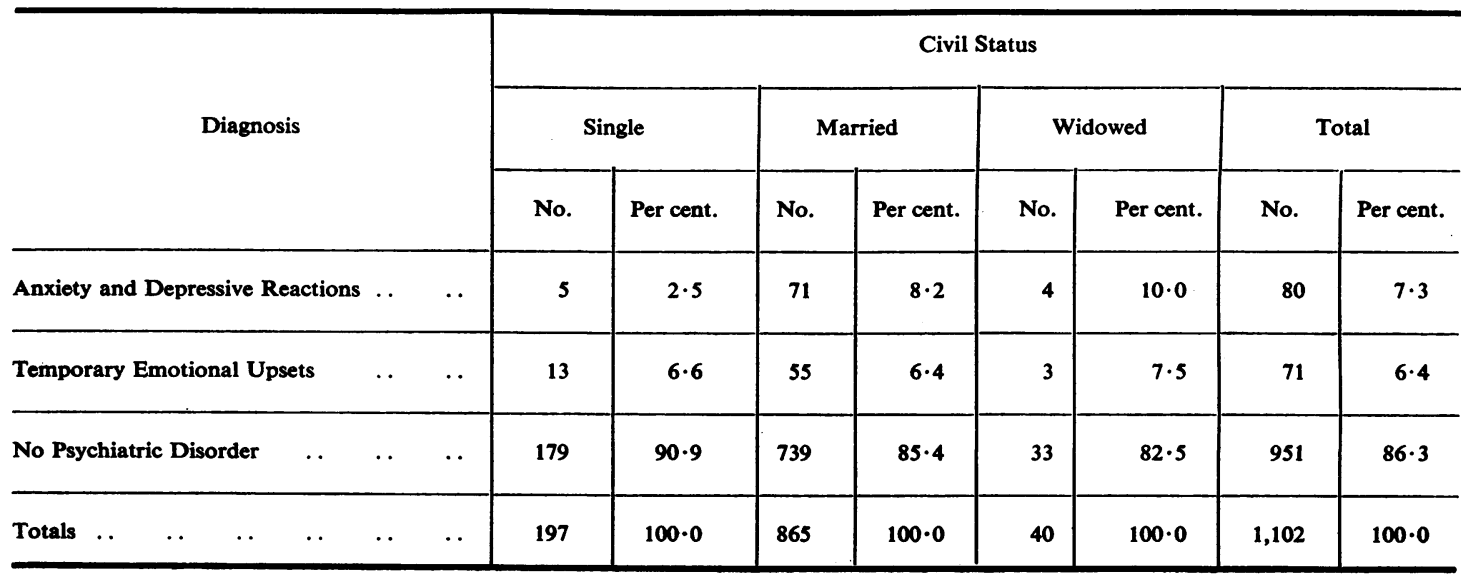


and Lazarsfeld, 1938). It is not perhaps justifiable to compare the subjects of these studies with the contemporary housewife, but a recent commentator (Lancet, 1960) points out that, when the children are at school and the housework is reduced to a minimum by modern appliances, "she is likely to question her own reason for existence and to feel a vague but pervasive dissatisfaction". This is clearly fertile soil for neurosis.

It must also be remembered that the social consequences of employment are not confined to providing occupation. The additional income may relieve financial worry, increase self esteem, and perhaps alter the status of the employed woman with her husband, family, and friends. A recent Sheffield investigation (Hodges and Smith, 1954) has shown that employed women have more friends than those who are solely housewives. These changes in the social environment are not irrelevant to the production of neurosis, and are among the factors which are so often uncontrolled in epidemiological studies. On the other hand, as well as these social and economic benefits of occupation, the presence of neurotic symptoms may itself be a powerful motivation for a woman to seek employment outside her house, spurred on by the advice of her friends and the popular weeklies. It is this possibility which makes an inception study of more value than a prevalence study; many of the married neurotic women may have sought employment to alleviate their symptoms.

What does seem to be beyond dispute is the greater instability of the female psychological adjustment, and this is well shown by Table I. The trials of the female reproductive system are confidently blamed for this well-recognized fact, but
Logan and Cushion (1958) do not show any drop in psychiatric morbidity in the post-menopausal years, and this is in accord with the experience of this practice. It may well be that the female reproductive system is not so grave a psychological hazard as are the attitudes and expectations imposed by our society on those who possess it.

\section{SUMMARY}

(1) In a survey of psychiatric morbidity in a rural general practice of 3,000 patients, the increased prevalence in women is confirmed.

(2) Gainful occupation outside the home is not associated with any decrease in prevalence in women.

(3) It is suggested that the increased prevalence in women of psychiatric illness may be due to social and cultural factors which have yet to be identified.

\section{REFERENCES}

Brown, G. W., Carstairs, G. M., and Topping, G. (1958). Lancet, 2, 685.

Eisenberg, P., and Lazarsfeld, P. F. (1938). Psychol. Bull., 35, 358.

Hodges, M. W., and Smith, C. S. (1954). "The Sheffield Estate", in "Neighbourhood and Community", p. 79, University Press, Liverpool.

Lancet (1960). Annotation, 2, 1128.

Logan, W. P. D., and Cushion, A. A. (1958). General Register Office Studies on Medical and Population Subjects, No. 14, "Morbidity Statistics from General Practice", vol. 1 (General). H.M.S.O., London.

Morton, N.'W. (1935). "Occupational Abilities: A Study of Unemployed Men", p. 96. Oxford University Press. Toronto.

Stein, L. (1960). Brit. J. prev. soc. Med., 14, 9. 